\title{
Agente comunitário de saúde e o idoso: visita domiciliar e práticas de cuidado
}

\section{$I^{2}$ Audrey Silva de Assis, ${ }^{3}$ Carlos Roberto de Castro-Silva I}

Resumo: O crescimento da população idosa no Brasil vem ocorrendo de forma acelerada, configurando um grande desafio para os serviços públicos de saúde. A Estratégia Saúde da Família (ESF) indica uma mudança no modelo tradicional de atenção à saúde, pautado no viés do cuidado integral. Uma das principais atribuiçóes do agente comunitário de saúde (ACS) é a visita domiciliar, por meio da qual pode estabelecer um vínculo com as famílias atendidas e conhecer suas necessidades. O objetivo do estudo foi analisar o potencial da visita domiciliar como instrumento de prática de cuidado e fortalecimento de vínculo junto à população idosa em território de alta vulnerabilidade. Foram realizadas observaçóes participantes sistematizadas em diários de campo, além de entrevistas semiestruturadas com três agentes comunitários de saúde de uma Unidade de Saúde da Família. A construção de sentidos do material sistematizado em tabelas foi organizada a partir do referencial da análise do discurso, que abrange os sentidos intersubjetivos em uma interlocução com o contexto social. Observou-se que a visita domiciliar envolveu dinâmicas de acolhimento e vínculo afetivo construídas cotidianamente, o que fortaleceu as práticas de atenção aos idosos no território, produzindo construçóes criativas e singulares de cuidado.

O ACS ocupava um lugar afetivo-técnico importante na ESF, potencializando açôes de promoção à saúde de idosos na comunidade, ainda contribuindo para o incremento de políticas públicas voltadas para essa população.

> Palavras-chave: Estratégia Saúde da Família; agente comunitário de saúde; idoso; visita domiciliar; rede social de apoio.

\footnotetext{
1 Pesquisa financiada pelo

Programa Institucional de Bolsas de Iniciação Científica/Conselho Nacional de Desenvolvimento Científico e Tecnológico (PIBIC/ (NPq), no período de 2013 a 2014

${ }^{2}$ Universidade Federal de São Paulo. Santos -SP, Brasil (audreys7@hotmail.com). ORCID: 0000-0003-3649-3006.

${ }^{3}$ Políticas Públicas e Saúde Coletiva, Universidade Federal de São Paulo. Santos-SP, Brasil (carobert3@hotmail.com). ORCID: 0000-0002-8880-1042.
}

Recebido em: 27/09/2016 Revisado em: 08/02/2018 Aprovado em: 24/04/2018 


\section{Introdução}

A Estratégia Saúde da Família (ESF) se caracteriza por um conjunto de medidas articuladas, que visa à reorganização do sistema de saúde, a partir da atenção primária. Esta proposta adquire fôlego com a criação do Programa Saúde da Família (PSF), em 1994 (BRASIL, 1994). Isto contribui para que a ESF oriente o cuidado de acordo com uma lógica usuário-centrada, partindo de princípios como a garantia de acessibilidade a todas as pessoas e a reorganização dos processos de trabalho com foco no trabalho em equipe, princípios estes que fortalecem o estabelecimento de uma relação com os usuários baseada na solidariedade e na cidadania (BACKES et al., 2012; SILVA et al., 2013; FRANCO et al., 1999).

A equipe mínima da ESF é composta por médicos, enfermeiros, auxiliares de enfermagem e agentes comunitários de saúde (ACS). Suas principais atividades se dividem em visitas domiciliares (VD), açôes programáticas e atendimentos médicos ou de enfermagem na Unidade de Saúde da Família (USF) (FRANCO; MERHY, 2007). Os ACSs se configuram como importantes mediadores entre a população de uma determinada regiáo e o serviço de saúde. É importante lembrar que residem no mesmo território, sendo este um pré-requisito para o exercício da atividade, aspecto que contribui para que o profissional vivencie a mesma dinâmica e realidade das pessoas das quais cuidam. Dessa forma, pode-se inferir que, "por vivenciar os problemas e morar na comunidade em que desempenha a sua prática de trabalho, o ACS figura como importante elo de interlocução entre a equipe e o usuário, na produção do cuidado" (BEZERRA et al., 2005, p. 810).

A VD é um importante instrumento de cuidado na perspectiva da atenção básica em saúde e está entre as principais atividades estabelecidas para o ACS pelo Ministério da Saúde (MS) (BRASIL, 2001). A partir da VD, o ACS pode estabelecer o vínculo com as famílias atendidas e conhecer suas necessidades singulares de cuidado.

O cuidado por meio da VD acontece in loco, fornecendo subsídios ao ACS para o aprofundamento do conhecimento da realidade do seu território, do contexto de vida dos usuários e suas condiçôes de habitação, entre outros aspectos referentes às dinâmicas familiar e comunitária, o que contribui para o fortalecimento do vínculo entre profissionais e usuários do serviço de saúde (FILGUEIRAS; SILVA, 2011).

No entanto, após mais de 20 anos de implementação, a ESF ainda se depara com questôes amplas, que permeiam o processo saúde-doença, enfrentando desafios, 
tais como a sensibilização quanto ao envolvimento dos profissionais na reorientação do trabalho em saúde, a atenção à lógica de produção do cuidado, o aumento da responsabilização coletiva no trabalho em equipe, o trabalho organizado em eixo verticalizado e a prática da intersetorialidade (COSTA et al., 2009; SILVA et al., 2013).

A partir desses questionamentos, pode-se inferir que o papel de mediação proposto para o ACS não é tarefa fácil, pois suscita muitos conflitos, os quais revelam a complexidade da dinâmica de funcionamento da ESF. Além disso, tal situação é agravada pelas dificuldades que esses profissionais podem encontrar para lidar com os determinantes sociais intimamente relacionados ao território de alta vulnerabilidade. Sendo assim, esse contexto exige ainda mais da atuação do ACS, pois seu cotidiano de trabalho o faz se deparar com formas e intensidades diversas de sofrimentos a ser enfrentados, sugerindo que “[...] a potencialização da capacidade de ação dos ACSs suscita a elaboração dos dilemas e dificuldades atuais enfrentados cotidianamente em suas práticas nas comunidades" (SILVA et al., 2014, p. 685).

Entre a população atendida pela ESF, destacam-se os idosos, que solicitam formas de assistência diversas e, de acordo com as estatísticas, irão demandá-las ainda mais. Isto porque, atualmente, a perspectiva de envelhecimento populacional no Brasil se encontra em um crescente, como mostram os dados da Organização Mundial da Saúde (OMS): entre 1950 e 2025, a população de idosos no país crescerá 16 vezes, contra as cinco vezes do crescimento populacional total esperado, colocando o Brasil como um dos países com maior número de idosos no mundo (SANT'ANNA et al., 2003; BELTRÃO et al., 2004).

Esse panorama demográfico reforça a importância das pesquisas envolvendo a temática do envelhecimento, visto que a citada mudança demográfica vem ocorrendo de forma rápida e, em contrapartida, com pouca preparação no âmbito das políticas públicas voltadas para atendê-la (MIRANDA et al., 2016). Nesse sentido, faz-se evidente a importância da estruturação de um modelo de atenção à saúde do idoso que abarque as novas demandas sociais e de cuidado em saúde (CRUZ et al., 2010).

Estudo de Miranda et al. (2016) destaca uma redução nas internaçóes hospitalares de idosos por doenças dos aparelhos circulatório e respiratório, além do sistema endócrino, o que indica a possibilidade de esse panorama estar relacionado à expansão e à melhora da qualidade dos serviços de atenção básica.

Em 2005, foi estabelecida, pelo MS, uma agenda de compromissos, visando reforçar as ações em saúde na atenção básica, na qual está incluído o Pacto em 
Defesa da Vida. Nesse documento, o idoso é incluído nas perspectivas do cuidado integral e do atendimento dos profissionais de atenção básica de forma ampla e multidimensional (BRASIL, 2006).

Nesse sentido, a ESF adquire maior relevância na atenção à saúde dessa população, destacando-se, entre outros aspectos, o contato que se estabelece entre o idoso e o ACS, que é fonte de informações e reflexôes valiosas sobre o modo de vida, as necessidades e as expectativas da população idosa. Tal argumento é reforçado pela necessidade de se focar em açóes mais amplas, que abarquem uma aproximação maior entre as demandas da comunidade e a oferta de serviços da USF, pois tratar de promoção em saúde em um contexto de alta vulnerabilidade e carências é ampliar o olhar para as dinâmicas psicossociais que atravessam a produção de cuidado em determinado território.

Czeresnia (2003) discute que as perspectivas mais recentes sobre promoção de saúde enfatizam as açóes intersetoriais e incluem um sentido ampliado de ambiente, que considera as dinâmicas local e global, e ainda os aspectos psicossociais. Nesse sentido, "a ideia de promoção envolve a de fortalecimento da capacidade individual e coletiva para lidar com a multiplicidade dos condicionantes da saúde” (CZERESNIA, 2003, p. 47).

Assim, o presente artigo tem como objetivo principal analisar o potencial da VD como instrumento de prática do ACS no cuidado e no fortalecimento de seu vínculo afetivo e social junto à populaçáo idosa em território de alta vulnerabilidade.

\section{Metodologia}

\section{Breve caracterização do território}

De acordo com o Índice Paulista de Vulnerabilidade Social (IPVS) (SÃO PAULO, 2012), o município de Cubatão (SP) tem $21,2 \%$ de sua populaçáo no grupo Vulnerabilidade Alta e 21\% no grupo Vulnerabilidade Altíssima, ou seja, $42,2 \%$ de sua população exibem baixa condição socioeconômica, pois os chefes de família apresentam, comumente, baixas renda e escolaridade (SÃO PAULO, 2012).

O bairro da Vila dos Pescadores, localizado nesse município, constitui-se em espaço de ocupação dos manguezais da Baixada Santista, marcado pela dinâmica de transformaçóes do espaço urbano, as quais reforçam processos de exclusão social cristalizada ao longo das últimas décadas (ROSA, 2014). Observam-se graves 
problemas de infraestrutura no local, como moradias em sistema de palafitas, luz clandestina e esgoto a céu aberto. A USF representa um papel importante nesse território, visto que é a única representação do Estado no local (SILVA et al., 2014).

Lá estavam alocadas, no momento da pesquisa, duas equipes completas de USF, compostas por médicos, enfermeiros, auxiliares de enfermagem e ACS, além de psicólogos e fisioterapeutas do Núcleo de Apoio à Saúde da Família (Nasf), promovendo açôes de matriciamento pautadas nos princípios da integralidade e da intersetorialidade do trabalho em saúde.

A rotina de atendimento à população idosa contava principalmente com o trabalho de VD, o qual era realizado prioritariamente pelo ACS. Além disso, foram realizadas ações programáticas da ESF voltadas à prevenção de agravos à saúde, como campanhas de vacinação e atividades de grupos com pessoas diabéticas e hipertensas. Alguns eventos pontuais, como palestras educativas para os idosos, ainda estavam em fase de implantação, contando com baixa adesão da população durante o período de realização da pesquisa.

\section{Percurso metodológico}

Esta pesquisa qualitativa, de caráter exploratório e descritivo, foi realizada com ACS de uma USF localizada no município de Cubatão (SP). Todas as ACSs eram do sexo feminino, com faixa etária entre 29 e 40 anos, e a maioria possuía ensino médio completo.

Inicialmente, foi realizada uma breve exposição dos objetivos da pesquisa junto às ACSs, com o intuito de convidá-las a participarem da pesquisa e a esclarecer-lhes possíveis dúvidas, o que possibilitou a construção de uma boa aproximação com as trabalhadoras. Posteriormente, foram realizados os acompanhamentos das VDs direcionadas aos idosos nas respectivas microáreas, ao longo das semanas.

Esta pesquisa fez parte de um processo gradual de construção de vínculo com o território e junto às ACSs, pois tal aproximação se iniciou com as atividades referentes à pesquisa "A potência de ação de agentes comunitários de saúde do Programa Saúde da Família da Vila dos Pescadores em Cubatão-São Paulo"', realizada de 2011 a 2013, com subsídios do CNPq, a partir de aprovação no edital 14/2011. Cabe ressaltar que ambas as pesquisas tiveram inspiração na pesquisa participante, principalmente no que se refere ao desenvolvimento de atividades conectadas com as temáticas trazidas pelas ACSs, visando à pesquisa como instrumento de qualificação, bem como 
possíveis encaminhamentos de problemas vivenciados nos cotidianos de trabalho desses profissionais (SILVA et al., 2014).

Nesse sentido, optou-se pela escolha dos seguintes instrumentos de coleta de dados: observação participante e entrevistas semiestruturadas. Segundo GonzálezRey (2012), o processo de pesquisa está atrelado a uma constante interação entre o campo e o pesquisador, que favorece a criatividade e a autonomia deste último na construção de novas interpretaçóes da realidade pesquisada.

Foram realizadas 12 visitas ao campo, acompanhando, assim, a rotina de trabalho de diferentes ACSs. A partir dessas observaçôes, foram produzidos diários de campo utilizados na compreensão da dinâmica e do funcionamento do equipamento de saúde e da comunidade. As visitas aconteceram em diferentes dias da semana, ao longo de aproximadamente dois meses, tendo cada uma a duração de quase duas horas.

Foram realizadas, também, entrevistas semiestruturadas com três ACSs, baseadas em um roteiro previamente estabelecido, e orientadas para a temática do envelhecimento e as práticas de cuidado do idoso na ESF. Das entrevistas, foram convidadas a participar as ACSs que já estavam sendo acompanhadas nas VDs, como uma estratégia de aprofundamento das informações obtidas. As falas utilizadas para compor as análises e destacadas neste artigo serão identificadas pela sigla da nomenclatura da profissão ACS seguida de uma letra escolhida aleatoriamente, de forma a preservar o entrevistado.

A partir desta premissa, a sistematização das informaçóes foi realizada mediante tabelas estruturadas em categorias empíricas, as quais favoreceram a organização dos principais norteadores da análise de resultados. A construção de indicadores qualitativos referentes à experiência do ACS no cuidado do idoso, a partir da vivência da $\mathrm{VD}$, tem a função de problematizar a dimensão das práticas de cuidado aos idosos, as quais se dão no âmbito do vínculo afetivo e do acolhimento, e, ainda, ampliar o olhar para a importância desta estratégia enquanto tecnologia de cuidado.

O processo de organização e exame dos dados partiu do referencial teórico da análise do discurso, que, como discutido por Orlandi, "concebe a linguagem como mediação necessária entre o homem e a realidade natural e social” (2001, p. 15). Dessa forma, a análise do discurso abrange os sentidos produzidos em uma interlocução com as realidades material e social, considerando a relação língua-discurso-ideologia (ORLANDI, 2001; CAREGNATO; MUTTI, 2006). 
Cabe destacar que a presente pesquisa foi aprovada pelo Comitê de Ética em Pesquisa da Universidade Federal de São Paulo e pela Secretaria Municipal de Saúde do município de Cubatão (SP). O número de protocolo do parecer é 476.148, de 6 de dezembro de 2013 - Certificado de Apresentação para Apreciação Ética (CAAE) no 21051613.0.0000.5505. Destaque-se que os Termos de Consentimento Livre e Esclarecido (TCLE) foram obtidos.

\section{Resultados}

A oportunidade de vivenciar aspectos da realidade cotidiana do trabalho do ACS e de sua relação com a atenção dada aos idosos na comunidade propiciou uma melhor compreensão da complexidade de lidar com processos de saúde-doença-cuidado, em um território vulnerável. A observação da dinâmica intersubjetiva surge como aspecto importante na consideração do território e na construção de metodologias participativas (MORAES et al., 2017).

Nesse sentido, é importante ressaltar que tais vivências no território reforçaram a proposta da produção de conhecimento considerada a partir do reconhecimento do lugar do pesquisador e de sua capacidade de ser afetado pelos encontros com os participantes da pesquisa. Sobre este modelo de pesquisa, Moraes et al. (2017) destacam: "Pode ser um importante caminho para problematizar, promover reflexôes e dar espaço à criatividade de pesquisadores e pesquisados, além de propiciar transformaçôes nos sujeitos mediante as relaçóes intersubjetivas que se estabelecem" (p. 219).

Inicialmente, aponta-se para a VD enquanto promotora de um espaço de atenção permeado pela construção de vínculos afetivos. Em seguida, destacam-se experiências micropolíticas de cuidado que podem contribuir com a discussão do papel da VD, assim como seus desafios e fragilidades, na perspectiva da atenção ao idoso na ESF. Por último, são tecidas consideraçôes sobre os aspectos da afetividade e do reconhecimento implicados no aspecto relacional do trabalho do ACS.

A VD, também nesse território pesquisado, mostrou-se como o principal instrumento de aproximação e construção de vínculos com a comunidade. Araújo e Barbosa (2010), em seu estudo com ACS, reforçam que, no processo de atuação com o idoso, há o estabelecimento de uma relação de otimismo, amizade e atenção, que possibilita a criação de vínculos promotores de saúde com os próprios idosos 
e seus familiares. Considerando este panorama relacional do trabalho, é possível caracterizar a atuação do ACS na perspectiva das tecnologias leves, visto que tal atuação privilegia a qualidade do vínculo que se estabelece com o outro (MERHY; FEURWERKER, 2007), como se vê no seguinte depoimento:

[...] eles precisam de atenção. A gente não tem que ter pressa, tem que fazer as visitas e pensar mesmo que a gente "tá ali naquela visita pra tentar resolver o problema do idoso" (ACS A).

Ao mesmo tempo que é importante ressaltar a potência da VD no fortalecimento da confiança na equipe, nota-se, por outro lado, que o ACS está mais suscetível a tensôes e sobrecargas, visto que se torna o depositário de expectativas da comunidade, com relação ao serviço de saúde (JARDIM; LANCMAN, 2009). Sobre a relação com o idoso, as ACSs destacaram, logo de início, a carência de atenção que eles sentem:

A gente vai fazer uma visita com idoso, sempre demora mais do que com uma pessoa comum, né? Porque vai falar mais do remédio, da receita, disso, daquilo, do dia a dia... E aproveita pra falar da rotina, né?(ACS A).

Mas, às vezes, a gente passa e eles começam a falar dos problemas, se queixar da vida; começa a falar dos filhos, da vida... (ACS D).

De acordo com Cunha e Sá (2013), determinados tipos de açôes em saúde extrapolam o âmbito da clínica, pois suscitam implicaçóes éticas com os usuários, gerando responsabilização e compromisso social. Para as ACS aqui mencionadas, a VD foi considerada o principal esteio desse apoio mais qualificado, todavia percebeu-se que houve uma valorizaçáo maior, da parte do serviço de saúde, do cumprimento da cota mensal de visitas, ofuscando a tônica de um trabalho que deve se dar principalmente pela qualidade das interaçôes humanas (SILVA et al., 2014):

[...] que era "só" esse: fazer as visitas, perguntar como a pessoa está, se tem alguma necessidade, se as receitas estão em dia, se alguém ficou internado, ou precisa de visita (Diário de Campo 3 - 18.12.2013).

Apesar da exigência burocrático-institucional, que mina a construção de um trabalho mais consistente no território junto às pessoas, observa-se que a aproximação da ACS com o cotidiano da populaçáo permite a obtenção de interpretaçóes mais aguçadas da realidade e das dificuldades que os idosos enfrentam, alimentando a criaçáo de formas singulares de cuidado, ou seja, mais sintonizadas com o contexto e as necessidades específicas daquelas pessoas. 
Essa perspectiva vai ao encontro do que se propóe com o trabalho vivo em ato, como discutido por Merhy (2002). Isto significa que o encontro entre profissional e usuário resulta em processos de trabalho nos quais o primeiro coloca seu saber à disposição do segundo, enquanto tecnologia de cuidado (MERHY, 2002). Para o autor, a criatividade do profissional exemplifica a capacidade apresentada pelo processo de trabalho para comportar o atravessamento de diferentes lógicas. Ou seja, em sua ação, o profissional está aberto à presença do trabalho vivo em ato:

Ela, então, montou uma caixa e organizou os remédios para a idosa, colando figuras para ela lembrar do horário do medicamento (Diário de Campo 9 - 28.02.2014).

O ACS deve elaborar práticas de cuidado que atendam a seu fazer generalista, mas que compreenda e considere as demandas da pessoa atendida, de forma a potencializar o cuidado oferecido. Zenchetta et al. (2015) definem como informaçôes qualitativas relevantes o apanhado de informaçóes resultantes do trabalho do ACS não documentadas no registro de saúde, mas que podem evidenciar aspectos comportamentais, afetivos e sociais, e que, através de uma leitura pelo viés dos determinantes sociais, também podem beneficiar seu trabalho.

Ainda nesse sentido, pode-se discutir o trabalho do ACS a partir da proposta da integralidade, destacada por Mattos (2006) como uma postura integral, que se estabelece no encontro que se dá entre profissional e usuário, a partir de processos de trabalho que olhem as necessidades dos usuários em termos de cuidados técnicos, e, em contrapartida, da consideração das precisôes de saúde que extrapolem a prevenção e o controle de doenças. Em uma das VDs, esse tipo de sintonia ficou evidente:

A ACS trouxe os medicamentos e eu a ajudei a anotar numa folha, de forma legível e clara, as informações de quantidade, pois, na receita, as informaçôes estavam bem difíceis de serem entendidas (Diário de Campo 9 - 28.02.2014).

As práticas de cuidado ofertadas pela ACS implicam um reconhecimento das necessidades de cuidado da família em questáo. De acordo com Cunha e Sá (2013), a VD pode construir práticas de cuidado que, indo na contramão das práticas médicas dominantes, considerem a realidade, as necessidades e os limites da vida das pessoas, contribuindo para o fortalecimento das açôes da ESF. É importante destacar que o trabalho do ACS é potencializado à medida que se articula com o trabalho em equipe, embora seu lugar seja muitas vezes marginalizado dentro das decisóes e dos encaminhamentos (FRUTUOSO et al., 2015): 
Então, contou que, nas visitas que realizava, já mapeava a necessidade do idoso, se era necessária a visita do médico, se era algum outro tipo de necessidade (Diário de Campo $1-09.12 .2013)$.

Esses argumentos reiteram a importância da atenção primária em saúde, a partir da qual o trabalho do ACS contribui para a construção de uma rede de cuidado em que se torna possível a prevenção de agravos à saúde do idoso, levando-se em conta que "a atenção primária em saúde possui a particularidade de conseguir prevenir condiçóes incapacitantes e prevalentes na terceira idade, caso consiga estar corretamente orientada para seus atributos" (MARTINS et al., 2014, p. 3413).

No percurso de acompanhamento das VDs com as ACSs, foi possível visitar diferentes microáreas, o que favoreceu uma visão ampliada de diferentes realidades vivenciadas pelos idosos na comunidade, destacando-se a busca de compreensão do estabelecimento de redes de cuidados e apoio social ao idoso.

Sabe-se que o estabelecimento de redes sociais entre os moradores da comunidade pode ser observado de diferentes modos, inclusive através da relação com a equipe de saúde, que pode ser um ponto de referência para a construção dessa rede de suporte social (MENDES; AKERMAN, 2014). Além disso, é importante destacar a intersetorialidade como uma forma de integrar as açôes em busca de um cuidado ampliado, visto que o ACS pode se deparar com situações que estejam para além de sua atuação ou do suporte oferecido pela USF.

Dessa forma, considera-se que essa prática de cuidado desencadeada pelo ACS ao idoso passa a ter maior efetividade quando amparada por açóes intersetoriais, principalmente quando se leva em consideração o impacto dos determinantes sociais no cuidado ao idoso. No caso do território estudado, observou-se que parte significativa da construçáo de redes sociais de suporte aos idosos aconteceu mediada pelo apoio da comunidade. Segundo o relato da ACS, havia uma descrença em relação à potencialidade institucional, destacando a USF:

Conversando sobre suporte na comunidade, a ACS enfatiza que, em relação aos vizinhos, é o mais que tem. Inclusive, tem mais que na saúde. Segundo ela, os vizinhos ajudam mais do que as próprias pessoas (da saúde) (Diário de Campo 9 - 28.02.2014).

Cabe ressaltar que esse caráter de envolvimento da comunidade no cuidado aos idosos deve ser levado em conta, haja vista a potência desta nas práticas de cuidado e na construção de redes sociais no território (BRAGA, 2006). Foi possível observar que, nesse território, as formas mais expressivas de construção de redes advêm da 
família, do território por meio dos vizinhos e da relação com o equipamento de saúde, nesse caso, a USF.

Em recente revisão de literatura, Gouveia et al. (2016) destacaram estudos que indicavam o efeito positivo das relaçóes de amizade e de vizinhança no tocante às redes familiares. Além disso, também discutiram os achados que indicavam os benefícios do estabelecimento de relaçóes sociais simultâneas e seu impacto na qualidade de vida de idosos.

Discussões em estudos têm demonstrado a importância das redes sociais como promotoras de solidariedade entre as pessoas, inclusive indicando que a pobreza de relaçôes sociais é fator de risco à saúde, se comparado a outros fatores nocivos (BROADHEAD et al., 1983 apud ANDRADE; VAITSMAN, 2002). Assim, de acordo com Domingues et al. (2007), "o fato de conhecermos as inserçôes dos indivíduos a partir de suas redes micro sociais nos permite inferir sobre as suas possibilidades de acessar os recursos comunitários e, portanto, deduzir sua posição na sociedade" (2007, p. 771).

$\mathrm{Na}$ descrição de alguns momentos de acompanhamento do trabalho das ACS junto aos idosos, nos quais o acolhimento e a escuta qualificada se mostraram determinantes para a construção de vínculo afetivo e de cuidado, percebe-se que diferentes manifestações de agradecimento e reconhecimento consolidam e, ao mesmo tempo, arejam o potencial desse cuidado. É possível fazer uma leitura desta dinâmica entre as ACSs e os idosos, a partir da teoria da dádiva, que se refere à "obrigatoriedade de dar, receber e retribuir os bens simbólicos e materiais entre doadores e donatários, e se configura como uma teoria antiutilitarista da açáo" (LACERDA; MARTINS, 2013, p. 209). Em relação à importância do reconhecimento, destaca-se o fato de que, "ao me sentir reconhecido, eu também passo a me reconhecer como um sujeito com valores e singularidades [...] ao reconhecer o outro, estou admitindo o seu valor enquanto sujeito" (CAILLÉ, 2008 apud LACERDA; MARTINS, 2013):

Então, às vezes, eu sinto até um carinho deles por mim, né? Pelo fato d'essa confiança... e querer falar da vida deles, particular, pr'a gente. É bom (ACS A).

A gente é praticamente... é tudo... É a família para ele. Eles abraçam a gente muito bem assim, quando a gente vai lá, tipo, recebe muito bem (ACS V).

Considera-se que, a partir da percepção do ato de reconhecimento, como uma via de mão dupla, os idosos assumem um lugar de protagonismo na construção de vínculo com o ACS, gerando reciprocidade entre ambos. Lacerda e Martins 
(2013) indicam que a circulação de afetos possibilita a sensação de amor, aceitação e valorização, e o reconhecimento mútuo.

Isso implica que, ao me sentir reconhecido, eu entro em 'dívida' com o reconhecedor, fazendo com que a dívida simbólica se transforme novamente em dádiva e realimente os vínculos sociais, e engendre a formação de novas redes de apoio social (LACERDA; MARTINS, 2013, p. 202).

Esse tipo de vinculação, em que a mbos se sentem valorizados, reforça a percepção do ACS como um sujeito ativo na construção de processos de saúde-doença e cuidado, extrapolando a ideia arraigada, do ponto de vista mecanicista, de um portador de informaçôes da comunidade para o serviço de saúde e vice-versa (SILVA et al., 2014). Ainda, é importante destacar, nesta discussão sobre o reconhecimento, a solidariedade, especialmente em seu potencial democrático, na medida em que incentiva a mobilizaçáo dos sujeitos em torno de transformaçôes sociais, valorizando as dimensôes da autonomia e da liberdade desses atores sociais (LAVILLE, 2009 apud LACERDA; MARTINS, 2013).

Assim, essa experiência envolve a circulação da dádiva e implica o reconhecimento e a construção afetiva da autoestima, à medida que o sujeito se reconhece valioso para os demais e reconhece o valor do outro. Nesse sentido, a circulaçâo da dádiva realimenta os vínculos sociais, de forma a manter a tríade doação-recepçãoretribuição (LACERDA; MARTINS, 2013).

\section{Considerações finais}

As práticas do ACS são pautadas principalmente pelo acolhimento e pela escuta atenta, os quais são a base da relação com os idosos. Embora a VD seja uma relação que se inicia com as solicitaçôes de preenchimentos de fichas de cadastramento de dados sociodemográficos e o acompanhamento de doenças mais prevalentes na população, este contato dá abertura para a criação de estratégias de cuidado e redes de suporte significativas entre serviço de saúde e comunidade. Zanchetta et al. (2015) consideram que os ACSs são capazes de obter informaçôes valiosas através desta experiência, que envolve a comunicação e o estabelecimento de vínculo, atravessado pela sensação de solidariedade e confiança.

É importante lembrar que a experiência do ACS no cuidado à população idosa faz parte das orientaçóes da Política Nacional de Saúde da Pessoa Idosa, que define a atenção básica em saúde como porta de entrada para o cuidado da saúde da população 
idosa, estabelece a atenção integral à saúde, bem como estimulaçôes intersetoriais, e valoriza a formação e a educação dos profissionais do SUS na área de saúde da pessoa idosa, entre outras diretrizes (BRASIL, 2006).

Os ACSs são capazes de oferecer um modelo de suporte social que tem como características principais a consolidação de polos de apoio, que funcionam como referência no auxílio ao enfrentamento de problemas cotidianos e pontuais, ocorrentes em momentos de crise (BRAGA, 2006).

Este trabalho não esgota a temática, mas ressalta novas possibilidades de investigação na construção de práticas de cuidado integral à saúde do idoso no contexto da atenção básica, incluindo a valorização do trabalho do ACS, assim como a contribuição da capacitação desse profissional na perspectiva do envelhecimento. ${ }^{1}$

\section{Referências}

ANDRADE, G. R. B.; VAITSMAN, J. Apoio social e redes: conectando solidariedade e saúde. Ciênc. Saúde Colet., v. 7, n. 4, p. 925-934, 2002.

ARAÚJO, M. A. S.; BARBOSA, M. A. Relação entre o profissional de saúde da família e o idoso. Esc. Anna Nery, v. 14, n. 4, p. 819-824, 2010.

BACKES, D. S. et al. Significado da atuação da equipe da Estratégia Saúde da Família em uma comunidade socialmente vulnerável. Ciênc. Saúde Colet., v. 17, n. 5, p. 1151-1157, 2012.

BELTRÃO, K. I.; CAMARANO, A. A.; KANSO, S. Dinâmica populacional brasileira na virada do século XX. Rio de Janeiro: IPEA, 2004.

BEZERRA, A. F. B.; ESPÍRITO SANTO, A. C. G.; BATISTA FILHO, M. Concepções e práticas do agente comunitário na atenção à saúde do idoso. Rev. Saúde Pública, v. 39, n. 5, p. 809-815, 2005.

BRAGA, N. A. Redes sociais de suporte e humanizaçáo dos cuidados em saúde. In: DESLANDES, S. F. (Org.). Humanização dos cuidados em saúde: conceitos, dilemas e práticas. Rio de Janeiro: FIOCRUZ, 2006, p. 163-183.

BRASIL. Gabinete do Ministro de Estado da Saúde. Portaria no 2528, de 19 de outubro de 2006. Aprova a Política Nacional de Saúde do Idoso e dá outras providências. Brasília, 2006. Disponível em: <http://portal.saude.gov.br/portal/arquivos/pdf/2528\%20aprova\%20a\%20politica\%20 nacional\%20de\%20saude\%20da\%20pessoa\%20idosa.pdf>. Acesso em: 3 jun. 2014.

. Ministério da Saúde. Portaria GM no 399, de 22 de fevereiro de 2006. Manual Pacto pela Saúde 2006: consolidação do SUS. Brasília, 2006. Disponível em: <http://dtr2001.saude. gov.br/sas/PORTARIAS/Port2006/GM/GM-399.htm>. Acesso em: 15 nov. 2014. 
- Programa de Saúde da Família. Brasília: COSAC, 1994.

Secretaria Executiva. Programa Agentes Comunitários de Saúde - PACS. Brasília, 2001. Disponível em: <http://bvsms.saude.gov.br/bvs/publicacoes/pacs01.pdf>. Acesso em: 15 nov. 2014. CAREGNATO, R. C. A.; MUTTI, R. Pesquisa qualitativa: análise do discurso versus análise de conteúdo. Texto Contexto Enferm., v. 15, n. 4, p. 679-84, 2006.

COSTA, G. D. et al. Saúde da família: desafios no processo de reorientação do modelo assistencial. Rev. Bras. Enferm., v. 62, n. 1, p. 113-118, 2009.

CRUZ, D. T.; CAETANO, V. C.; LEITE, I. C. G. Envelhecimento populacional e bases legais da atenção à saúde do idoso. Cad. Saúde Colet., v. 18, n. 4, p. 500-508, 2010.

CUNHA, M. S.; SÁ, M. C. A visita domiciliar na estratégia de saúde da família: os desafios de se mover no território. Interface (Botucatu), v. 17, n. 44, p. 61-73, 2013.

CZERESNIA, D. O conceito de saúde e a diferença entre prevenção e promoção. In: CZERESNIA, D.; FREITAS, C. M. (Org.). Promoção da Saúde: conceitos, reflexóes, tendências. Rio de Janeiro: Ed. Fiocruz, 2003, p. 39-53.

DOMINGUES, M. A. et al. As redes sociais na senescência. In: PAPALÉO NETO, M. Tratado de Gerontologia. São Paulo: Atheneu, 2007, p. 771-780.

FILGUEIRAS, A. S.; SILVA, A. L. A. Agente Comunitário de Saúde: um novo ator no cenário da saúde do Brasil. Physis, v. 21, n. 3, p. 899-916, 2011.

FRANCO, T. B.; BUENO, W. S.; MERHY, E. E. O acolhimento e os processos de trabalho em saúde: o caso de Betim, Minas Gerais, Brasil. Cad Saúde Pública. Rio de Janeiro, v. 15, n. 2, p. 345-353, 1999.

FRANCO, T. B.; MERHY, E. E. Programa de Saúde da Família (PSF): contradiçóes de um programa destinado à mudança do modelo tecnoassistencial. In: MERHY, E. E. (Org.). O trabalho em saúde: olhando e experienciando o SUS no cotidiano. São Paulo: Hucitec, 2007, p. $55-124$.

FRUTUOSO, M. F. et al. Gestão local em território de vulnerabilidade: motivaçóes e racionalidades. Saúde em Debate, v. 39, n. 105, p. 337-349, 2015.

GONZÁLEZ-REY, F. Pesquisa qualitativa em psicologia: caminhos e desafios. São Paulo: Pioneira Thompson Learning, 2005.

- Pesquisa qualitativa e subjetividade: os processos de construção da informação. São Paulo: Cengage Learning, 2012.

GOUVEIA, O.; MATOS, A. D.; SCHOUTEN, M. J. Redes sociais e qualidade de vida dos idosos: uma revisão e análise crítica da literatura. Revista Brasileira de Geriatria e Gerontologia, v. 19, n. 6, p. 1013-1023, 2016. 
JARDIM, T. A.; LANCMAN, S. Aspectos subjetivos do morar e trabalhar na mesma comunidade: a realidade vivenciada pelo agente comunitário de saúde. Interface. Botucatu, v. 13, n. 28, p. 123-135, 2009.

LACERDA, A.; MARTINS, P. H. A dádiva no trabalho dos Agentes Comunitários de Saúde: a experiência do reconhecimento do amor, do direito e da solidariedade. Realis Rev. Estud. Antiutilitaristas Pós-Coloniais, v. 3, n. 1, p. 194-213, 2013.

MARTINS, A. B. et al. Atenção Primária à Saúde voltada às necessidades dos idosos: da teoria à prática. Ciênc. Saúde Colet., v. 19, n. 8, p. 3403-3416, 2014.

MATTOS, R. A. Os sentidos da integralidade: algumas reflexóes acerca de valores que merecem ser defendidos. In: PINHEIRO, R.; MATTOS, R. A. (Orgs.). Os sentidos da integralidade na atenção e no cuidado à saúde. Rio de Janeiro: IMS/UERJ, 2006, p. 43-68.

MENDES, R.; AKERMAN, M. Intersetorialidade: reflexões e práticas. In: Fernandez, J.C.A.; MENDES, R. (Org.). Promoção da Saúde e Gestão Local. São Paulo: Hucitec, 2014 , p. 100-128.

MERHY, E. E. A micropolítica do trabalho vivo em ato: uma questão institucional em território de tecnologias leves. In: . Saúde: a cartografia do trabalho vivo. São Paulo: Hucitec, 2002, p. 55-124.

MERHY, E. E.; FEUERWERKER, L. M. Atenção domiciliar: medicalização e substitutividade. Rio de Janeiro: Universidade Federal do Rio de Janeiro, 2007. (Micropolítica do Trabalho e o Cuidado em Saúde.) Disponível em: <http://www.medicina.ufrj.br/micropolitica/pesquisas/ atencaodomiciliar/textos.php>. Acesso em: jan. 2017.

MirandA, G. M. D.; MENDES, A. C. G.; SILVA, A. L. A. Population aging in Brazil: current and future social challenges and consequences. Rev. Bras. Geriatr. Gerontol., v. 19, n. 3, p. 507-519, 2016.

MORAES, R. C. P. et al. Pesquisa Participante na estratégia saúde da família em territórios vulneráveis: a formação coletiva no diálogo pesquisador e colaborador. Trab. educ. saúde, v. 15, n. 1, p. 205-222, 2017.

ORLANDI, E. P. Análise do discurso: princípios e procedimentos. Campinas: Pontes, 2001.

ROSA, K. R. M. A afetividade, o sofrimento ético-politico e o cuidado à saúde mental em território de alta vulnerabilidade social. 2014. Dissertação (Mestrado em Ciências da Saúde) - Universidade Federal de São Paulo, Santos, 2014, p. 205.

SANT'ANNA, R. M.; CÂMARA, P.; BRAGA, M. G. C. Mobilidade na terceira idade: como planejar o futuro? Textos sobre Envelhecimento, v. 6, n. 1, p. 9-30, 2003.

SÃO PAULO. Secretaria de Desenvolvimento Social. Mapa da Ação Social. Disponível em: <http://www.desenvolvimentosocial.sp.gov.br/mapa/>. Acesso em: 8 abr. 2012. 
SILVA, C. R. C. et al. Participação social e a potência do agente comunitário de saúde. Psicol. Soc., v. 26, n. 2, p. 113-123, 2014.

SILVA, C. R. C. et al. Extensão universitária e prática dos agentes comunitários de saúde: acolhimento e aprendizado cidadão. Saude soc., v. 23, n. 2, p. 677-688, 2014.

SILVA, L. A.; CASOTTI, C. A.; CHAVES, S. C. L. A produção científica brasileira sobre a Estratégia Saúde da Família e a mudança no modelo de atenção. Ciênc. Saúde Colet., v. 18, n. 10, p. 221-232, 2013.

TEIXEIRA, R. R. O acolhimento num serviço de saúde entendido como uma rede de conversações. In: PINHEIRO, R.; MATTOS, R. A. Construção da integralidade: cotidiano, saberes e práticas em saúde. Rio de Janeiro: IMS/UERJ, 2005, p. 49-61.

ZANCHETTA, M. S. et al. Brazilian community health agents and qualitative primary healthcare information. Prim. Health Care Res. Dev., v. 16, p. 235-245, 2015.

\section{Notas}

${ }^{1}$ A. S. de Assis concebeu e desenvolveu todas as etapas da pesquisa. C. R. de Castro-Silva orientou, contribuiu com a análise e discussão dos dados e realizou revisão teórico-metodológica do artigo. 


\section{Abstract}

\section{Community health agent and the elderly: home visit and care practices}

The growth of the elderly population in Brazil has been occurring in an accelerated way, configuring a great challenge for the public health services. The Family Health Strategy (FHS) indicates a change in the traditional model of health care, based on the integral care bias. One of the main tasks of the community health agent (CHA) is the home visit, through which you can establish a bond with the families and meet their needs. This study aimed to analyze the potential of the home visit as an instrument of care practice and strengthening of bond with the elderly population in a highly vulnerable territory. Participant observations were systematized in field diaries, as well as semistructured interviews with three community health agents from a Family Health Unit. The construction of meanings of the material systematized in tables was organized from the discourse analysis framework, which covers the inter-subjective senses in an interlocution with the social context. It was observed that the home visit involved dynamics of affection and daily affection, which strengthened the practices of attention to the elderly in the territory, producing creative and unique constructions of care. The ACS occupied an important affective-technical place in the FHT, promoting actions for the health of the elderly in the community, still contributing to increase public policies aimed at this population.

> Keywords: Family Health Strategy; community health worker; aged; home visit; social support network. 